\title{
Erratum: Japanese students' perceptions of the role that shadow education plays in competition in education
}

\section{MÁRTA FÜLÖP ${ }^{1,2}$ and JÁNOS GORDON GYÖRI ${ }^{3 *}$}

\footnotetext{
${ }^{1}$ Institute of Cognitive Neuroscience and Psychology, Research Centre of Natural Sciences, Eötvös Loránd Research Network, Budapest, Hungary

${ }^{2}$ Károli Gáspár University of the Reformed Churches, Budapest, Hungary

${ }^{3}$ Eötvös Loránd University, Institute of Intercultural Psychology and Education, Budapest, Hungary
}

\section{ERRATUM}

Published online: July 2, 2021

(c) 2021 The Author(s)

ERRATUM: Hungarian Educational Research Journal 11 (2021) 2, 143-165

DOI: $10.1556 / 063.2021 .00059$

The authors' affiliations were published incorrectly in the Online First version.

The correct form of the affiliations is as follows:

\section{Márta Fülöp ${ }^{1,2}$}

\section{János Gordon Győri ${ }^{3^{*}}$}

${ }^{1}$ Institute of Cognitive Neuroscience and Psychology, Research Centre of Natural Sciences, Eötvös Loránd Research Network, Budapest, Hungary

${ }^{2}$ Károli Gáspár University of the Reformed Churches, Budapest, Hungary

\footnotetext{
*Corresponding author. E-mail: gyori.janos@ppk.elte.hu
} 
${ }^{3}$ Eötvös Loránd University, Institute of Intercultural Psychology and Education, Budapest, Hungary

*Corresponding author. E-mail: gyori.janos@ppk.elte.hu

Open Access. This is an open-access article distributed under the terms of the Creative Commons Attribution-NonCommercial 4.0 International License (https://creativecommons.org/licenses/by-nc/4.0/), which permits unrestricted use, distribution, and reproduction in any medium for non-commercial purposes, provided the original author and source are credited, a link to the CC License is provided, and changes - if any - are indicated. 